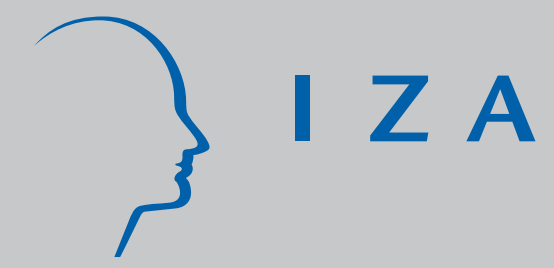

IZA DP No. 3611

Multi-Family Households in a Labour Supply Model: A Calibration Method with Application to Poland

Peter Haan

Michal Myck

J uly 2008 


\title{
Multi-Family Households in a Labour Supply Model: A Calibration Method with Application to Poland
}

\author{
Peter Haan \\ DIW Berlin \\ Michał Myck \\ DIW Berlin, IFS and IZA
}
Discussion Paper No. 3611
July 2008

IZA

P.O. Box 7240

53072 Bonn

Germany

\author{
Phone: +49-228-3894-0 \\ Fax: +49-228-3894-180 \\ E-mail: iza@iza.org
}

\begin{abstract}
Any opinions expressed here are those of the author(s) and not those of IZA. Research published in this series may include views on policy, but the institute itself takes no institutional policy positions.

The Institute for the Study of Labor (IZA) in Bonn is a local and virtual international research center and a place of communication between science, politics and business. IZA is an independent nonprofit organization supported by Deutsche Post World Net. The center is associated with the University of Bonn and offers a stimulating research environment through its international network, workshops and conferences, data service, project support, research visits and doctoral program. IZA engages in (i) original and internationally competitive research in all fields of labor economics, (ii) development of policy concepts, and (iii) dissemination of research results and concepts to the interested public.
\end{abstract}

IZA Discussion Papers often represent preliminary work and are circulated to encourage discussion. Citation of such a paper should account for its provisional character. A revised version may be available directly from the author. 


\section{ABSTRACT}

\section{Multi-Family Households in a Labour Supply Model: A Calibration Method with Application to Poland*}

The collective model of labour supply opened the household "black box" and allowed for individual treatment of partners in couples. However, the literature on labour supply has so far largely ignored a broader issue with special relevance to transition and developing countries - the distinction of single versus multi-family ("complex") households. We propose a method to account for multi-family household structure by borrowing from recent applications of the collective model and combining estimation and calibration to identify the degree of resource sharing. We assume that each household is characterised by a betweenfamily sharing parameter, which is calibrated on estimated preferences, the observed labour market status and other characteristics. The key identifying assumption is that preferences over income and leisure of specific family types living in single and multi-family households are the same conditional on observable characteristics. We apply the method to Polish labour market data.

JEL Classification: J22, 138, D13

Keywords: work incentives, within-household sharing, labour supply, transition

Corresponding author:

Michał Myck

DIW Berlin

Mohrenstrasse 58

10117 Berlin

Germany

E-mail: mmyck@diw.de

\footnotetext{
* Data from the Polish Household Budgets Survey and the SIMPL micro-simulation model for Poland used in this paper were provided by the micro-simulation research group based at the Department of Economics at the University of Warsaw (www.simpl.pl). The SIMPL model has been developed with the support of the Polish Ministry of Labour and Social Policy. We are very grateful to Leszek Morawski for his assistance with the model. The paper has benefited from comments and suggestions of seminar participants at SITE, IZA, IFS and DIW. We would also like to thank Francois Laisney and Viktor Steiner for very helpful suggestions. Peter Haan thanks for the financial support of the DAAD. The usual disclaimer applies.
} 


\section{Introduction}

Following Grossbard-Shechtman (1984), Chiappori (1988) and Chiappori (1992), there has been an increasing interest and a growing body of literature analysing the implications of within-household sharing of resources between individuals who constitute the household. Chiappori's collective model of labour supply allows for identification of individual preferences and a sharing rule which determines the allocation of resources in the household 1 This is in contrast to the traditional unitary models which treat the couple as a decision-making unit, and ignore the bargaining and allocation processes that go on within it. The relatively straightforward application of the unitary model in a discrete framework - especially following the method proposed by Aaberge et al. (1995) and van Soest (1995) - make it by far the more often used. However, recent advances in the development of the collective methodology (e.g.: Chiappori (1997) and Blundell et al. 2005)) and successful applications of the model which combined estimation and calibration, such as Beninger et al. (2006), have demonstrated that ignoring the processes that take place within the household lead to misleading conclusions concerning the behaviour of individuals in couples.

Although the collective model has opened the household "black box" and allowed for individual treatment of partners in couples, the labour supply literature has so far ignored a broader issue, namely the distinction between single versus multifamily/complex households. This distinction has special relevance for developing and transition countries, but it is also important for developed countries with more "traditional" household structures like Italy or Spain. If we define a "family" to be either a single adult or a couple with or without dependent children then a household can be made of more than one such family. There may of course be various combinations of single and couple families as well as families with individuals of working-age and beyond it. Such combinations, with a potential for resource sharing among the families, will have implications for the financial situation of each family, and as a consequence, for the financial incentives to work faced by each member of the household $2^{2}$

\footnotetext{
${ }^{1}$ For a description of the literature on within-household sharing see for example Vermeulen (2002) and Bargain et al. (2006).

${ }^{2}$ There exists an important strand of the literature in development economics focusing on withinhousehold division of resources with special focus on market and non-market work (e.g. Fefchamps and Quisumbing (2003)). The studies in development literature on intrahousehold sharing rely on detailed data about division of labour and resource sharing between members of the household. Our approach attempts to deal with the issue of resource sharing in "complex" households without specific
} 
In many developing countries but also in transition economies and several developed economies multi-family households are very common and are often an important source of income insurance. In this respect, multi-family households partly substitute for governmental transfer programs. Therefore, it seems that without a way to account for sharing of resources among families within households, modelling of work incentives and individual labour supply responses within such complex households may be incorrect.

We propose a way to address this problem by borrowing from recent applications of the collective model and combining microsimulation, estimation and calibration methods to identify the degree of sharing among families in households. Such combination has been successfully used in the context of the collective model for single family households (e.g. Beninger et al. (2007), Myck et al. (2006), or Vermeulen et al. (2006)). The method we develop is applied to Polish data. In Poland a substantial proportion of single adult families and couples - both with and without children live in multi-family households (MFHs). To present the methodology in the clearest way we focus in our application on the labour supply behaviour of single working age men and women without children who live together with one other family. Singles in Poland, in particular men, have a relatively low labour market attachment. This is observed in parallel with very low levels of governmental out-of-work transfers. As we demonstrated earlier (Haan and Myck (2007)) this puzzling combination of low employment and low benefits can be partly explained by the large share of singles living in MFHs who may receive intra household transfers through sharing.

The methodology we propose is contrasted with a simple extension of the "standard" model of labour supply, in which we control for characteristics of these complex households like demographic composition and income. We demonstrate that while the average results of our calibrated and the extended standard model are similar, the distribution of the results suggests important differences between groups. This may lead to wrongful conclusions concerning the implications of changes in financial incentives.

The model developed here, while focusing on single men and women, can be generalised and extended to analyse the labour supply of couples living in MFHs as well as to MFHs with more than two families. Other standard extensions of labour supply models, like modelling of childcare costs, could also be accounted for.

information on how resources are divided between household members. 
The approach provides only a non-structural solution to the problem of multifamily households by using calibration. Our application focuses on a combination of a labour-supply flexible adult individual living with a family the labour supply of which would be considered "fixed" or exogenous in most labour supply applications $3^{3}$ In such combinations it is impossible to specify the standard form of the utility function over consumption and leisure for all household members. As a consequence our method focuses only on the identification of the most likely financial incentives faced by the labour supply flexible family. This implies that the degree of resource "sharing" which we identify does not have a structural interpretation, e.g. bargaining power or egoism.

The paper is organised as follows. In Section 2 we set out the stage for the analysis by presenting the degree and type of multi-family household arrangements in Poland. We also specify the sub-sample of such households which our detailed analysis focuses on in the following sections. In Section 3 we present the details of the method we propose for the identification of the sharing parameter in MFHs. The method is then applied in Sections 4 and 5 in which we also present results of the analysis. Conclusions follow in Section 6 .

\section{Multi-family households in Poland}

The empirical analysis is based on the Polish Household Budgets' Survey from 2005. This is a representative survey for the Polish population with details concerning demographic information, consumption and incomes on nearly 35,000 households. The data presents a very interesting pattern of living arrangements which seems rather unique by the standards of most countries of the developed world. If we define a family to be either a single adult or couple (with or without dependent children), then over $30 \%$ of households in Poland consist of more than one family, and in over $7 \%$ of households there are more than two. This may have important consequences for the implications of government policy for changes in income distribution and labour market incentives.

In our data set there are 48,617 families of which 9,829 are families with at least

\footnotetext{
${ }^{3}$ Below we refer to labour supply flexible families as "LS-flexible" and to families without any LS-flexible individuals as "LS-fixed". In our approach individuals are assumed to be LS-fixed if they are retirement or disability pensioners, are in retirement age or full-time students. The claim of exogeneity of the labour market position may be judged as a strong assumption. However, given the very different administrative and labour demand constraints faced on the labour market by those assumed by us to be "LS-fixed" any other approach would have to rely on even stronger assumptions.
} 
one person of pension age; 17,344 are single working-age adult families, and 21,444 are couples where both spouses are in working age.

Since we focus on labour supply we are principally interested in households where at least one family is "LS-flexible", i.e. includes someone who is neither on retirement nor disability pension and is not a student (the age restriction we apply is 25-59). We exclude households with someone who is self-employed since it is difficult to estimate their incomes. This leaves us with a sample 19,834 families in 16,069 households. 11,601 are single-family households, while the remaining 8,233 families share their households with other families. In the Appendix in Table 8 we present various combinations of living arrangements for the labour supply flexible families in the sample. Couples are divided into three sub-categories conditional on the labour market flexibility of either of the partners (both flexible, man flexible, woman flexible).

As we can see while a large proportion of LS flexible families live in SFHs, almost $42 \%$ share their household with other families. The largest group of those $(3,797$ families in the sample) shares the household with one other LS-fixed family, but there are numerous other complex household arrangements. In our analysis we focus on single-adult families without children and we use the sample of single-family households and the sub-sample of two-family households which include a single LS-flexible adult and another LS-fixed family. In the case of single adults without children (see in Table 9 in the Appendix) the majority lives in "complex" households (75.4\%), and of those over a third live with one other LS-fixed family. In the application we use the 1148 single adult families from SFHs and 1271 families from MFHs. Descriptive statistics on the samples are presented in Tables 1 and 2 respectively for single men and single women.

We find interesting differences in the working behaviour for single men and women both in MFHs and SHFs. In contrast to the working behaviour of spouses in couples, we find that single women without children have higher participation rate than men. Over the combined sample of single women in MFHs and SFHs, more than $74 \%$ of women work. In contrast, single men have a lower employment rate at $61 \%$. It is also interesting that single men are more likely to work part-time compared to women. Some of these differences might be demand side driven, e.g. men tend to work in professions with higher unemployment. Moreover, activity in the shadow economy or seasonal work in and out of Poland might be higher for men, and this information may 
Table 1: Descriptive statistics by employment state: Single men without children

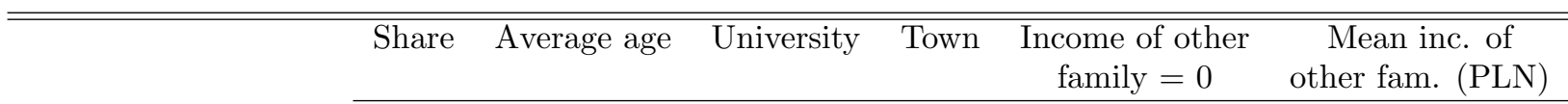

Number of obs: 1177

Out of work

$\begin{array}{llll}0.38 & 41.22 & 0.07 & 0.69\end{array}$

Part-time work

0.07

40.86

0.06

0.43

Full-time work

0.54

36.85

0.25

0.73

All

38.79

0.17

0.69

Number of obs: 415

Out of work

Part-time work

$$
0.25
$$

0.10

48.26

44.44

Full-time work

0.64

38.86

All

41.83

Single family households

Number of obs: 762

Out of work

0.46

38.92

$0.06 \quad 37.6$

35.41

0.48

37.13

$\begin{array}{ll}0.07 & 0.77 \\ 0.07 & 0.49 \\ 0.35 & 0.82 \\ 0.25 & 0.77\end{array}$

Multi family households

\begin{tabular}{|c|c|c|c|c|c|c|}
\hline & & & & & & \\
\hline Part-time work & 0.06 & 37.6 & 0.04 & 0.37 & 0.00 & 577.45 \\
\hline Full-time work & 0.48 & 35.41 & 0.17 & 0.67 & 0.02 & 754.91 \\
\hline All & & 2712 & 012 & 065 & 0.01 & 740.33 \\
\hline
\end{tabular}

Notes: "Income of other family $=0$ " - proportion of households where income of the LS-fixed family is zero. "Mean inc of other fam." - mean monthly income of the LS-fixed family conditional on it being positive. Statistics for multi-family households are only for those where a single LS-flexible person shares the household with an LS-fixed family. PLN - Polish zloty.

Source: Authors' calculations using BBGD, 2005.

not be reflected in the data. However as men and women in couples are faced with the same economic situation yet exhibit different working behaviour, the supply side is also likely to be responsible for the different working pattern we observe.

As we can see both single men and women in SFHs are slightly older than those in MFHs, and they are more likely to have completed university education. Single men in SFHs are twice more likely to have a university degree compared to those in MFHs. Singles living in MFHs are more likely to be found in villages than in the urban areas. It is also interesting to note that education and employment levels among single family households are higher for women compared to men.

As expected the proportion of employed individuals in SFHs is higher compared to MFHs. This large difference provides the key motivation for our analysis. The question we address is to what extent the multi-family household structure contributes to weakening the financial incentives for LS-flexible individuals over and above the consequences of them having different observable characteristics. 
Table 2: Descriptive statistics by employment state: Single women without children

\begin{tabular}{cccccc}
\hline \hline Share & Average age & University & Town & $\begin{array}{c}\text { Income of other } \\
\text { family }=0\end{array}$ & $\begin{array}{c}\text { Mean inc. of } \\
\text { other fam. (PLN) }\end{array}$ \\
\hline
\end{tabular}

Number of obs: 1242

Out of work

0.25

Individuals in single and multi family households

Part-time work

0.06

46.95

Full-time work

0.69

43.85

0.10

0.76

All

41.54

0.2

0.74

43.03

0.45

0.82

$0.35-0.80$

Number of obs: 733

Out of work

0.23

51.2

Single family households

Part-time work

0.06

46.19

Full-time work

0.71

42.56

44.74

$\begin{array}{cc}0.072 & 0.79 \\ 0.15 & 0.72 \\ 0.49 & 0.88 \\ 0.38 & 0.85\end{array}$

All

Multi family households

Number of obs: 509

Out of work

0.28

42.02

0.13

0.74

0.07

0.28

0.79

0.03

Full-time work

0.66

49.97

0.40

0.73

0.07

40.56

0.32

0.73

0.07

641.81

All

Notes: "Income of other family $=0$ " - proportion of households where income of the LS-fixed family is zero. "Mean inc of other fam." - mean monthly income of the LS-fixed family conditional on it being positive. Statistics for multi-family households are only for those where a single LS-flexible person shares the household with an LS-fixed family. PLN - Polish zloty.

Source: Authors' calculations using BBGD, 2005.

\section{Accounting for sharing of resources in multi-family households.}

\subsection{Within-household sharing of resources}

In any household resources can be shared in a multitude of ways, including extreme situations where all resources are appropriated by one household member and scenarios where they are shared among all individuals equally. Since the families we observe live under a "common roof" it is most likely that each of the families gets some share of the household resources, with the roof being the least each member can get.

In our approach we shall consider a spectrum of sharing scenarios between two extremes. One extreme is the situation in which resources are shared equally in accordance with equivalised family size ("full-sharing"), the other where every family keeps what it has, i.e. where there is no sharing. This spectrum of sharing scenarios 
excludes the possibility that any member of the household can force the others to part with more resources than the amount given by the "full-sharing" scenario. We assume that there is a single sharing rule for the entire household and that sharing is determined between families. In the case of households with more than two families the fact that there is a single sharing rule for the household may not necessarily hold, since there may be a greater degree of sharing between some families and less sharing between others. Since in our application we focus only on two-family households this simplification will not affect our results, but it should be considered carefully in possible extensions. Naturally resources can be shared in any fashion falling between "full sharing" and "no sharing". Let's say that a household $h$ is made of $F$ families which are denoted by $i$. Let income of each family in the scenario with no sharing of resources be $Y_{i}^{N S}$, and let the equivalence weight of each family be $\eta_{i}$. This means that income of family $i$ in the "full sharing" scenario will be:

$$
Y_{i}^{F S}=\frac{\eta_{i}}{\sum_{f=1}^{F}\left(\eta_{f}\right)} * \sum_{f=1}^{F}\left(Y_{f}^{N S}\right),
$$

where $F$ is the number of families in the household.

Let's define $\alpha_{h}$ to be the within-household sharing parameter for household $h$ taking values from 0 ("no sharing") to 1 ("full sharing" as in equation 1). Then income of each family, $Y_{i}^{S}$, given the household specific degree of sharing can expressed as:

$$
Y_{i}^{S}=Y_{i}^{N S}+\alpha_{h}\left(Y_{i}^{F S}-Y_{i}^{N S}\right)
$$

An important restriction which we have to impose is the "symmetry" of resource sharing across employment states. The sharing parameter $\alpha$ which we calibrate in the application is assumed to be stable regardless of whether a family is out of work (and say receives income through sharing), or is in work (and may be a "net" contributor to resources of the other family).

Naturally, family resources may substantially differ depending on the degree of sharing of resources within the household and sharing will strongly affect the financial incentives to work for the LS-flexible family. The importance sharing may have on financial incentives to work is presented in Figure 1 where we plot the distribution of replacement ratios (RRs) computed at family level as ratios of out-of-work to full-time 
in-work incomes. The figures are presented separately for men and women living in MFHs in our sample $11 \mathrm{~A}$ and $1 \mathrm{~B}$ respectively). With no sharing (i.e. where $\alpha=0$ ) both for men and for women the median replacement ratio is zero. With full sharing, as defined in equation 1, median RRs are 0.62 and 0.54 , respectively, and as one could expect the entire distributions of RRs shift to the right for higher values of the degree of sharing.

The reason for such significant effects of sharing on financial incentives is primarily that in a great majority of cases the LS-flexible family occupies the household with a family with some positive value of family income (see Tables 1 and 2). Only 1\% of single LS-flexible men and $8 \%$ of single LS-flexible women share households with families which do not have any income. Usually the values of (equivalised) incomes are relatively high and they are on average higher for households with single LSflexible men (735.60 PLN) than for those with single LS-flexible women (588.40 PLN). Interestingly the average values of incomes of LS-fixed families are similar for fulltime employed and not-employed single LS-flexible families. It is only for the parttime employed that we can see some difference in the average level of LS-fixed family incomes. The part-time employed, however, represent only small fractions among the respective family types.

Thus while resource sharing is very likely to affect financial incentives to work, its degree cannot be observed in the data. Below we propose a way to identify the $\alpha_{h}$ parameter by combining estimated labour market preferences of SFHs families and the observed behaviour of family members in MFHs.

\subsection{Assumptions necessary to identify the sharing parameter}

The identification of individual or family preferences concerning the leisure-consumption trade-off relies almost entirely on the correct measurement of disposable incomes in various labour market scenarios. Without knowing how resources are shared in MFHs, these disposable incomes cannot be reliably computed. Below we combine matching, estimation and calibration procedures to allow for the identification of the sharing parameter in each MFH.

The first step in the procedure is estimation of preference parameters for single individuals living in SFHs. In the following we will denote families in SFHs with $l$. 
Here we follow the standard procedure by directly estimating preferences over leisure and consumption using a discrete choice labour supply model ${ }^{4}$ In the discrete choice framework agents choose amongst $J$ discrete alternatives of employment states.

We assume that the labour market choice of family $i$ living in a MFH denoted with $h$ is a result of maximising a utility function of the following deterministic form:

$$
V_{i j}^{h}=U\left(\hat{\beta}, Z_{i}, L_{j}, Y_{i j}^{N S}, Y_{h j}^{N S}, \alpha_{h}\right), j \in\{0,1,2 \ldots, J\}
$$

$Z_{i}$ is a vector of demographic characteristics, $L_{j}$ is the leisure time at different labour market states $j, Y_{i j}^{N S}$ is the net income at employment state $j$ under the assumption of no sharing, and $Y_{h j}^{N S}$ is the net income of other household members if individual $i$ chooses the state $j$ (also under the assumption of no sharing). $\alpha_{h}$ is the household sharing parameter and vector $\hat{\beta}$ is a set of preference parameters estimated on the population of individuals or single families who live in SFHs. We thus make an assumption that conditional on $Z_{i}$, preferences over income and leisure of single adult individuals living in SFHs and MFHs are the same. Then the only unknown element necessary to determine the labour supply behaviour of family $i$ is $\alpha_{h}$. For identification we make use of the additional piece of information which is available in the data, namely the actual labour market choice of family $i$ in the MFHs.

The method of "borrowing" preferences from one population group and applying it to another has been used before in the literature, recently in the application of the collective model of labour supply in Beninger et al. (2007), Beninger et al. (2006), Myck et al. (2006), or Vermeulen et al. (2006). In these applications the assumptions were much stronger compared to those we make in this paper, as in these instances preferences of single individuals (without children) were used for individuals living in couples (with or without children). In our case we use preferences of single individuals (without children) living in SFHs to represent preferences of singles (also without children) in MFHs. While this is still a strong assumption it seems much less restrictive since the samples are much more similar, and it seems much more plausible to argue that conditional on observable characteristics preferences of these two groups of singles are the same. In addition to observed variables, unobservable characteristics might be differently distributed between SFHs and MFHs. In the matching procedure described

\footnotetext{
${ }^{4}$ We follow the standard assumption in this literature that families do not save nor borrow and therefore consumption is equal to net income.
} 
below we have tried to account for potential unobservable effects. As unobservables could not be robustly identified, we need to rely on the assumption the unobservable characteristics between SFHs and MFHs have the same distribution.

It is also important to note that the method we propose differs from that given in Vermeulen et al. (2006), in that our identification of the degree of sharing does not rely on preferences over leisure and income of both families in the households we analyse. As we mentioned earlier this is because it is impossible to identify such preferences for the LS-fixed family. The method proposed here uses only the income information of the LS-fixed family and identifies the degree of sharing within the household using the observed labour market state of the LS-flexible family. The degree of sharing we calibrate is not derived from a structural model of within-household division of resources, and thus should not be interpreted as a degree of power or selfishness of one family versus the other. Being derived in a non structural set-up it should purely be treated as a parameter which determines financial incentives of the labour supply flexible family.

\subsection{Identifying the sharing parameter}

Since the labour supply is modelled in a discrete model the calibration of the $\alpha_{h}$ parameter has to be conducted using expected probabilities of the discrete states. Define the expected probability of being in employment state $e$ of a family $l$ in a SFH who is actually observed in state $e$ to be:

$$
\hat{P}_{l}\left(j=e \mid \hat{\beta}, Z_{l}, Y_{l}, L_{j}, j=e\right),
$$

where $Y_{l}$ and $L_{j}$ are vectors of disposable incomes and leisure in all labour market states $j$ family $l$ can choose from.

Analogously, let's define the expected probability of being in employment state $e$ of an individual $i$ in a MFH who is actually observed in state $e$, to be:

$$
\hat{P}_{i}\left(j=e \mid \hat{\beta}, Z_{i}, Y_{i}^{N S}, Y_{h}^{N S}, \alpha_{h}^{k}, L_{j}, j=e\right)
$$

where $Y_{i}^{N S}$ and $Y_{h}^{N S}$ are vectors of the family's and other household members' incomes at each labour market scenarios $j$ available to family $i$, and $\alpha_{h}^{k}$ is a specific value of $\alpha_{h}$ such that $\alpha_{h}^{k} \in[0,1]$. 
For each chosen value of $\alpha_{h}^{k}$ and for every chosen pair of observations $i$ and $l$ we can compute the following expression of "distance":

$$
\varphi_{i, l}^{h, k}=\left[\sum_{j=1}^{j=J}\left({\hat{P_{i, j}}}^{h, k}\right)-\sum_{j=1}^{j=J}\left(\hat{P_{l, j}}\right)\right]^{2} .
$$

In equation 6 the distance $\varphi_{i, l}^{h, k}$ is expressed as a squared difference of the sums of expected probabilities of being employed $(j>0)$. For a given set of $Y_{i}^{N S}, Y_{h}^{N S}$ and $Y_{l}$ this distance will be different depending on the chosen level of $\alpha_{h}^{k}$. Naturally $\varphi_{i, l}^{h, k}$ will also be different for a given set of $Y_{i}^{N S}, Y_{h}^{N S}$ and $\alpha_{h}^{k}$ and for varying levels of financial incentives of the SFH, $Y_{l}$.

The last piece in the jigsaw to identify the $\alpha$ parameter is the appropriate way to match the single adult families in SFHs and MFHs. In our application this is done using employment propensity score matching. For every single adult family in a MFH we match a number $\mathrm{N}$ of "nearest" single adult families living in SFHs. We conduct the matching separately for men and women and it is done conditional on the observed employment status. More precisely, we estimate the employment propensity for all single adults based on detailed educational and regional information, the health status and age $5^{5}$ In this sense this estimation can be seen as a reduced-form labour market participation model without accounting directly for the financial incentives. We have experimented with several specifications of the employment propensity, by making use of the part time information and allowing for flexible interactions. ${ }^{6}$

The distance $\varphi_{i, l}^{h, k}$ can be computed for a chosen number of different values of the sharing parameter $\alpha$ for every MFH for each of the nearest SFHs. This results in $\mathrm{N}$ different values of the $\alpha$. The average of $\mathrm{N} \alpha$ 's (weighted by the proportional distance in propensity scores) is taken to represent the household sharing parameter.

\section{Estimating the labour supply}

As discussed above, the identifying assumption for the estimation of the labour supply behaviour of single individuals in MFHs is that they have the same preferences for

\footnotetext{
${ }^{5}$ Estimation results can be obtained by the authors upon request.

${ }^{6}$ To relax the assumption about non-random selection in MFHs and SFHs we have estimated a discrete choice model of participation with random effects. However, given the cross-sectional variation, the identification of this model was not reliable.
} 
consumption and work as individuals in SFHs. For the latter group we can estimate the preferences conditional on observable characteristics directly from the data in a static structural discrete choice model of labour supply, as e.g. in Aaberge et al. (1995) or in van Soest (1995). The estimated coefficients are then used to describe the conditional preferences for consumption and work of singles in MFHs which allows the identification of the sharing parameters given the observed labour market behaviour of singles in MFHs.

The discrete choice approach for the estimation of labour supply behaviour has the essential advantage over a continuous specification of the working hours that the non-linearities in the budget set caused by the tax and transfer system can be easily incorporated and that the potential endogeneity problem of income can be solved. Moreover, the information on working hours in the Polish BBGD data is classified into three discrete categories as: no work, part-time and full-time. The Polish distribution of hours worked (available for example in the Polish LFS data) suggests that most parttime employment is half-time, and we assume this to be the case for all who declare part-time employment in the BBGD. The three points of work intensity describe the working behaviour of the single households.

Thus consistent with the expression for the utility function of individuals living in MFHs specified in Equation (3), we assume that a family $l$ living on his or her own receives utility $V_{l j}$ at each discrete hours point $j$. This utility is assumed to depend on a function $U$ of disposable income $Y_{l j}$ which determines consumption, on demographic characteristics $Z_{l}$, on leisure $L_{j}$ and on a random term $\epsilon_{l j}:^{7}$

$$
V_{l j}=U\left(Y_{l j}, Z_{l}, L_{j}\right)+\epsilon_{l j} j \in\{1,2, \ldots, J\}
$$

Following McFadden (1974) we assume that the error terms $\epsilon_{l j}$ follow an extreme value distribution, and therefore the discrete choice model can be estimated by conditional logit. The likelihood to be maximized is then:

$$
L=\prod_{l=1}^{N} \prod_{j=1}^{J} \operatorname{Pr}\left(Y_{l}=j\right)^{d_{l j}}
$$

\footnotetext{
${ }^{7}$ More complex specifications with household specific unobserved heterogeneity could not be identified.
} 
where $d_{l j}=1$ if $j$ is the chosen alternative and 0 otherwise, and $\operatorname{Pr}\left(Y_{l}=j\right)$ is the choice probability for alternative $j$.

The household specific disposable income at each working alternative is derived with the Polish microsimulation model SIMPL 8 We specify the leisure time as the total weekly time budget minus the state specific working hours. Income and leisure enter in a linear quadratic specification. Preferences for income and leisure are made conditional on age, education and regional information. 99 For identification the observables are interacted with the state specific net-household income and the leisure time. Table 3 presents results of the labour supply estimation separately for men and women who live in SFHs. In addition, we present estimation results for what we call the "extended standard" model, i.e. a labour supply model including singles living in SFHs and MFHs. In this specification incomes of the LS-flexible families are taken at the family level assuming no sharing, but we account for the additional household income in MFHs to control for its effect on labour market behaviour. This treatment does not explicitly take account of potential sharing, but it represents an extension of the standard approach in cases of complex households. This specification will be used as a benchmark for comparing the performance of the calibrated model below.

The interpretation of the estimated coefficients is not too informative due to the numerous interactions and the non-linearity of the discrete choice model. Instead we derive labour supply elasticities based on the estimated coefficients which describe the working behaviour. We derive the change in the participation rate measured in percentage points with respect to a $1 \%$ increase in gross hourly wages. We use a calibration method which is consistent with the probabilistic nature of the model at the individual level (Creedy and Duncan, 2002). It consists of drawing for each household a large number of $J$ random terms from the extreme value distribution that generates a perfect match between predicted and observed choices. The same draws are kept when predicting labour supply responses to a shock on wages. Averaging individual supply responses over a large number of draws provides robust transition matrices. The mean elasticities are presented in the bottom of the table. Interestingly, the elasticities for men are higher than women. This is true when focussing only at the SFHs as well when considering the full sample. For SFHs the change in the participation rate amounts to

\footnotetext{
${ }^{8}$ For more details on the Polish microsimulation model see Bargain, Morawski, Myck, and Socha (2007).

${ }^{9}$ For descriptive statistics see Section 2 .
} 
Table 3: Labor Supply Estimation

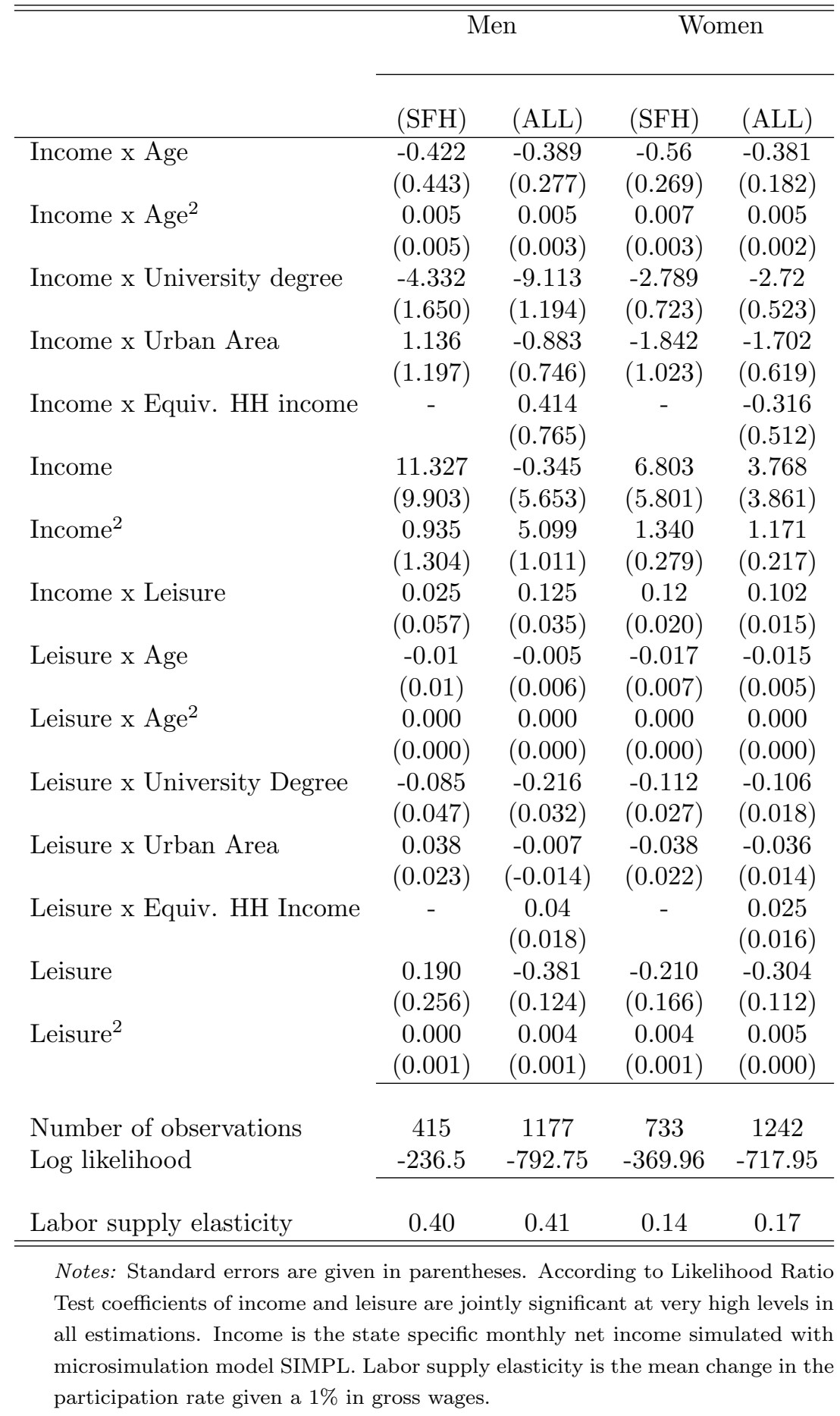


0.4 for the mean of men and 0.14 for the mean of women. The finding contrasts with gender specific labour supply elasticities in other countries which in general report higher elasticities for single women, in particular single mothers. However, given the characteristics of the population we consider the results seem plausible. As discussed above, Polish single men in general tend to have lower education and lower wages than single women and the participation rate of men and women is nearly the same. For the full sample we find a similar gender difference, with the elasticity of 0.17 for single women and 0.41 for single men. It is important to note that including the MFHs in the estimation, especially for men, does not change the elasticities in any important way.

\section{Calibrating the sharing parameter for singles in MFHs}

The calibration is conducted at the household level for 25 equally spaced values of $\alpha_{h}$ and in each case of a MFH we match $\mathrm{N}=10$ "nearest" SFHs as described above 10 The distribution of the calibrated values is presented in Table 4 , where the calibrated values of $\alpha$ are divided into five categories. The results are presented separately for men and women and conditional on the observed employment status.

Table 4: Distribution of the sharing parameter in two-family households

\begin{tabular}{|c|c|c|c|c|c|c|}
\hline \multirow[b]{3}{*}{$0<=\alpha<=0.2$} & \multicolumn{3}{|c|}{$\begin{array}{ll}\text { Men } \\
\end{array}$} & \multicolumn{3}{|c|}{ Women } \\
\hline & Not employed & $\begin{array}{l}\text { Employed } \\
\text { (col }\end{array}$ & $\begin{array}{c}\text { All } \\
\text { amn p }\end{array}$ & $\begin{array}{l}\text { Not employed } \\
\text { rcentages) }\end{array}$ & Employed & All \\
\hline & 7.2 & 31.1 & 20.2 & 12.6 & 32.8 & 27.1 \\
\hline $0.2<\alpha<=0.4$ & 23.9 & 28.7 & 26.5 & 19.6 & 30.9 & 27.7 \\
\hline $0.4<\alpha<=0.6$ & 23.1 & 23.6 & 23.4 & 25.9 & 18.9 & 20.8 \\
\hline $0.6<\alpha<=0.8$ & 25.9 & 9.9 & 17.2 & 26.6 & 10.1 & 14.7 \\
\hline $0.8<\alpha<=1$ & 19.9 & 6.7 & 12.7 & 15.4 & 7.4 & 9.6 \\
\hline Total observations & 347 & 415 & 762 & 143 & 366 & 509 \\
\hline
\end{tabular}

As we can see in Table 4 the method identifies a significant degree of within house-

\footnotetext{
${ }^{10}$ We conducted sensitivity analysis to check how results change to increasing the number of calibrated values for $\alpha_{h}$ and it did not affect the results.
} 
hold sharing of resources. Moreover the distribution of $\alpha$ parameters conditional on employment status is consistent with our expectations concerning the financial incentives individuals face on the labour market. For example while the values of the sharing parameter are between 0 and 0.2 (i.e. no or little sharing) for only about $7 \%$ of non employed men who live in MFHs, they are between 0.6 and 1.0 (i.e. a substantial degree of sharing) for as many as $45.8 \%$. On the other hand only $16.6 \%$ of employed men live in MFHs with such a high degree of sharing and for $31.1 \%$ we identify no or very little sharing. The pattern is similar for women, although it is slightly less pronounced for the non employed sample. Among employed women we find that $32.8 \%$ live in households with little sharing and $7.4 \%$ in those with $\alpha$ between 0.8 and 1 . It is notable that for a very high proportion of single adults in MFHs we find a high degree of sharing. The $\alpha$ parameter is above 0.4 for $53.3 \%$ of men and $45.1 \%$ of women.

It is important to stress once more that what is being identified as $\alpha$ is the most likely pattern of financial incentives the individuals face on the labour market. Thus the "degree of sharing" should not be interpreted in a structural way. For example, the fact that there is no sharing or low degree of sharing does not mean that families in these households do not share any of their costs of living or their meals. What low values of $\alpha$ imply is that the single individuals we observe behave on the labour market in such a way as if the financial incentives they face were determined without regard to incomes of other household members. This non-structural interpretation of the sharing parameter should be sufficient to be able to describe the labour supply behaviour of LS-flexible individuals in MFHs. From this point of view knowing what financial incentives these individuals respond to is all we need to know to model the effect of changes in these incentives.

An important way to verify the validity of the calibrated parameters is to examine the relationship of $\alpha$ 's to individual and household characteristics. One would expect for example that apart from some correspondence to characteristics of individuals, such as age or education, the calibrated values would also relate to characteristics which have so far not been used in the analysis and which could play a role in determining how resources are shared between the families ${ }^{11}$ In Table 5 we present results of regressing the calibrated $\alpha$ parameters on a set of individual and household

\footnotetext{
${ }^{11}$ In the terminology of the collective model of labour supply such characteristics could be termed as "distribution factors".
} 
Table 5: Determinants of the calibrated sharing parameters.

\begin{tabular}{lccc|ccc}
\hline \hline & \multicolumn{3}{c}{ Specification 1 } & \multicolumn{3}{c}{ Specification 2 } \\
\cline { 2 - 7 } Constant & Coeff. & S.e. & Sign. & Coeff. & S.e. & Sign \\
Employed & 0.0204 & $(0.1387)$ & & 0.1243 & $(0.1262)$ & \\
Age & - & - & & -0.2198 & $(0.0135)$ & $* * *$ \\
Age squared & 0.0226 & $(0.0070)$ & $* * *$ & 0.0285 & $(0.0063)$ & $* * *$ \\
Higher education & -0.0003 & $(0.0001)$ & $* * *$ & -0.0004 & $(0.0001)$ & $* * *$ \\
Male & 0.1708 & $(0.0197)$ & $* * *$ & 0.2092 & $(0.0180)$ & $* * *$ \\
Lives in a village & 0.0295 & $(0.0210)$ & & -0.0078 & $(0.0193)$ & \\
Lives in a village $*$ Male & 0.0644 & $(0.0251)$ & $* * *$ & 0.0713 & $(0.0228)$ & $* * *$ \\
& 0.0925 & $(0.0312)$ & $* * *$ & 0.0975 & $(0.0284)$ & $* * *$ \\
OTH: Age difference & -0.0012 & $(0.0009)$ & & -0.0016 & $(0.0008)$ & $*$ \\
OTH: higher education & -0.0806 & $(0.0302)$ & $* * *$ & -0.0605 & $(0.0275)$ & $* *$ \\
OTH: better educated & 0.1145 & $(0.0245)$ & $* * *$ & 0.0874 & $(0.0224)$ & $* * *$ \\
OTH: married & -0.0345 & $(0.0267)$ & & -0.0488 & $(0.0243)$ & $* *$ \\
OTH: married*male & 0.0677 & $(0.0313)$ & $* * *$ & 0.0779 & $(0.0285)$ & $* * *$ \\
OTH: parent/s & -0.0620 & $(0.0212)$ & $* * *$ & -0.0838 & $(0.0193)$ & $* * *$ \\
& & & & & & \\
Number of observations: & & 1271 & & & & \\
R squared & & 0.1183 & & & 0.2713 & \\
\hline \hline
\end{tabular}

Notes: OTH - characteristics related to the other (LS-fixed) family.

Source: Authors' calculations using BBGD, 2005.

characteristics (marked as OTH - for "other family" - in the table). We present two specifications, one without and one with controlling for employment status. Employment strongly correlates with the value of $\alpha$ and as expected correlates negatively with the degree of sharing. Higher education of the LS-flexible family correlates positively with sharing, and sharing increases with age. Households living in villages seem to have a higher degree of sharing. We can also see that the calibrated parameters correlate significantly also with such characteristics as university education of the head of the $L S$-fixed family, and with education level of the head of the $L S$-fixed family being higher than the education of the LS-flexible adult. Moreover marital status of the $L S$-fixed family also seems to matter. Interestingly living with an $L S$-fixed couple negatively correlates with the sharing parameter for women but positively for men. The age difference between the head of the $L S$-fixed family and the LS-flexible adult reduces the degree of sharing. Similarly if the LS-flexible family is a child of the other family (versus being parent or in some other relation) this also reduces the degree of sharing. 


\subsection{Within-household sharing and labour supply elasticity}

In the following we study in how far the identified degree of sharing matters for analysing changes in working incentives. Below we compare the responsiveness of individual labour supply for the model with calibrated sharing and for the "extended standard" model in the case of two types of changes in financial incentives:

- a $1 \%$ increase in the gross wage,

- a reduction in the employee rate of the disability Social Security Contribution from $6.5 \%$ to $1.5 \%$.

The first change is a standard measure of labour supply elasticity, while the second is a reform which was recently introduced in Poland (in two stages in July 2007 and January 2008).

The responses to these changes in financial incentives are computed in the same way as in the model for SFHs in Section 4. Elasticities are numerically derived using draws from the error terms and measure the change in the participation rate following the increases in the disposable net incomes. In Tables 6 and 7 we present two sets of responses for each of the reforms. One set is based on the calibrated approach while the other on the "extended standard" model described in Section 4 (below referred to as the "ES model"). Results are shown separately for men and women. In the Tables mean responses are shown for each subgroup defined by the value of the calibrated $\alpha$ as in Table 4. The tables also show average responses for the entire sample of LS-flexible families in MFHs.

Comparing the labour supply effects using the two different methods, we find some important variation by the category of the calibrated $\alpha$ parameter. However, the differences in overall means are relatively small. The mean gross wage elasticity for men in the ES model is 0.50, while in the calibrated approach it amounts to 0.56, i.e. only about $10 \%$ higher. For women the values are respectively 0.17 and 0.12 , i.e. about $30 \%$ lower. By the five categories of the sharing parameter the differences of the elasticities are striking. For example for men living in households with $\alpha$ between 0.2 and 0.4 the elasticity in the ES model is 0.52 , while that obtained with the calibrated method is 0.81 . For those in the highest $\alpha$ category $(0.8<\alpha<=1)$, the elasticities 
Table 6: Gross wage labour supply elasticity by household sharing rule

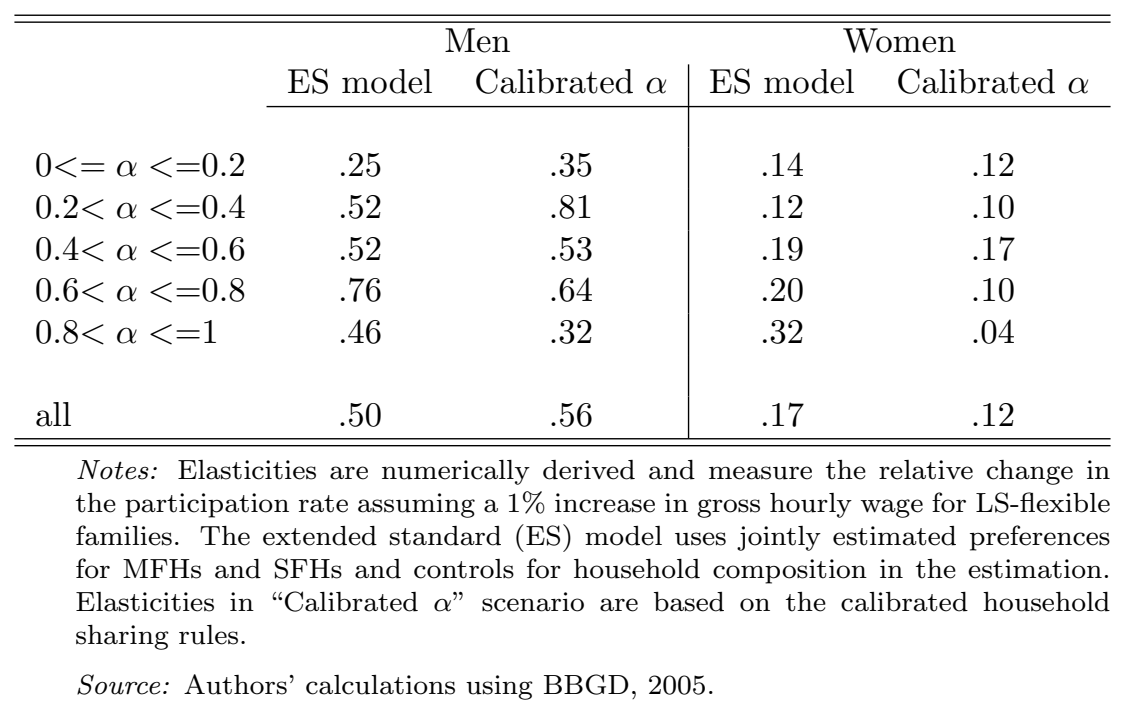

Table 7: Labour supply response following SSC-reform by household sharing rule

\begin{tabular}{lcc|cc}
\hline \hline & \multicolumn{2}{c}{ Men } & \multicolumn{2}{c}{ Women } \\
& ES model & Calibrated $\alpha$ & ES model & Calibrated $\alpha$ \\
\cline { 2 - 5 } $0<=\alpha<=0.2$ & 1.54 & 2.08 & 0.63 & 1.01 \\
$0.2<\alpha<=0.4$ & 3.47 & 4.68 & 0.77 & 0.84 \\
$0.4<\alpha<=0.6$ & 3.41 & 3.63 & 0.90 & 0.98 \\
$0.6<\alpha<=0.8$ & 4.40 & 3.73 & 1.54 & 0.71 \\
$0.8<\alpha<=1$ & 3.01 & 2.17 & 1.49 & 0.38 \\
all & & & & \\
\hline \hline
\end{tabular}

Notes: Elasticities are numerically derived and measure the relative change in the participation rate assuming a reduction in the SSC employee contributions (by 5 percentage points). The extended standard (ES) model uses jointly estimated preferences for MFHs and SFHs and controls for household composition in the estimation. Elasticities in "Calibrated $\alpha$ " scenario are based on the calibrated household sharing rules.

Source: Authors' calculations using BBGD, 2005.

are respectively 0.46 and 0.32 . For women the highest differences are for those living in households with high degree of sharing. For females living in households with $0.6<\alpha<=0.8$ the elasticity in the ES model is twice as high as that in the calibrated model, while for the highest $\alpha$ category it is 0.32 in the ES model but only 0.04 if we account for sharing using the calibrated method.

The comparison of the labour supply responses derived using the different methods highlights the importance to account for income sharing in a comprehensive way. The ES model underestimates the elasticity for individuals living in households with low degree of sharing, but it overestimates it for households with high degree of sharing. 
This bias is in line with the wrong depiction of the work incentives in the ES model. Work incentives for singles with a low degree of sharing are relatively strong as working income is the only source of income. On the other side, a high level of sharing can be seen as a transfer that reduces the work incentives. In contrast to the calibration method, the ES model does not account for the different sharing pattern and ceteris paribus the other family income provides the same incentives for all values of $\alpha$.

The differences can be seen for the gross wage elasticity for men (Table 6), and both for men and women in the case of the reaction to the SSC reform (Table 7). Looking at the results of the SSC reform, we find that the ES-model underestimates the response by about $26 \%$ for men (1.54 vs. 2.08) and by $38 \%$ for women (0.63 vs. 1.01 ) in the case of MFHs with $\alpha$ below 0.2. On the other extreme, for households with $\alpha$ greater that 0.8 , it overestimates it for men by about $40 \%$ (3.01 vs. 2.17) and for women by almost four times (1.49 vs. 0.38).

Thus, while the ES model seems to estimate the average response broadly right relative to the calibrated method, it may imply very wrongful predictions for different subgroups conditional on the degree of sharing in their households.

\section{Conclusion}

In this paper we have proposed a method to account for income sharing in MFHs which provides the possibility to analyse labour supply responses in complex households. In developing countries as well as in transition economies multi-family households are very common and are often an important source of income insurance. In this respect, multifamily households partly substitute for governmental transfer programs. Therefore, it seems that without a way to account for sharing of resources among families within households, modelling of work incentives and individual labour supply responses within such complex households may be incorrect.

Our approach is related to recent applications of the collective household model based on estimation and calibration techniques to identify the degree of resource sharing and labour supply responses. The important difference is that our approach is non-structural since we cannot specify the standard utility function over leisure and consumption for the LS-fixed families. However, similar to the method proposed in 
Vermeulen et al. (2006), our key identifying assumption is that preferences over income and leisure of specific family types living in single and multi-family households are the same conditional on observable characteristics.

With this assumption we identify the degree of sharing for Polish single men and women living together with another LS-fixed family. The results suggest a substantial degree of sharing in the multi-family households, and are consistent with the observed labour market status of single adults living in the MFHs. The degree of sharing is negatively correlated with the probability of being employed. The analysis also confirmed an important role of several characteristics of the LS-fixed family as determinants of the sharing rule. The sharing parameter correlates with age and education differences between the families, with the marital status of the LS-fixed family, and the relation between the families.

We find that calibrating the income sharing in MFHs is important to derive labour supply responses of single men and women. Whereas on average a standard labour supply model which is conditioned on other household income predicts similar labour supply elasticities as the proposed model, the simulated labour supply response markedly differs by the degree of sharing. While the standard model underpredicts the response for households with low degree of sharing, it substantially overpredicts the elasticity of households identified with high degree of sharing.

\section{References}

Aaberge, R., J. Dagsvik, and S. Strom (1995): "Labor Supply Responses and Welfare Effects of Tax Reforms," Scandinavian Journal of Economics, 97(4), 63559.

Bargain, O., M. Beblo, D. Beninger, R. Blundell, R. Carrasco, M. Chiuri, F. Laisney, V. Lechene, E. Longobardi, M. N., M. Myck, J. RuizCastillo, and F. Vermeulen (2006): "Does the representation of the household behaviour matters for welfare analysis of tax-benefit policies? An introduction," Review of Economics of the Household, 4, 99-111. 
Bargain, O., L. Morawski, M. Myck, and M. Socha (2007): "As SIMPL as That: Introducing a Tax-Benefit Micro-simulation model for Poland," IZA Discussion Paper No. 2988, IZA-Bonn.

Beninger, D., O. Bargain, M. Beblo, R. Blundell, R. Carrasco, M. Chiuri, F. Laisney, V. Lechene, E. Longobardi, M. N., M. Myck, J. RuizCastillo, and F. Vermeulen (2006): "Evaluating the move to a linear tax system in Germany and other European countries," Review of Economics of the Household, 4, 159-180.

Beninger, D., F. Laisney, and M. Beblo (2007): "Welfare Analysis of Fiscal Reforms: Does the Representation of the Family Decision Process Matter? Evidence for Germany," Journal of Population Economics, 20(4), 869-893.

Blundell, R., P.-A. Chiappori, and C. Meghir (2005): "Collective Labor Supply with Children," Journal of Political Economy, 113(6), 1277-1306.

Chiappori, P.-A. (1988): "Rational Household Labor Supply," Econometrica, 56, $63-89$.

(1992): "Collective Labor Supply and Welfare," Journal of Political Economy, $100,437-467$.

(1997): "Introducing Household Production in Collective Models of Labor Supply," Journal of Political Economy, 105, 191-209.

Creedy, J., And A. Duncan (2002): "Behavioural Microsimulation with labour supply responses," Journal of Economic Surveys, 16, 1-40.

Fefchamps, M., And A. R. Quisumbing (2003): "Social roles, human capital, and the intrahousehold division of labor: evidence from Pakistan," Oxford Economic Papers, 55(1), 36-80.

Grossbard-Shechtman, A. (1984): "A Theory of Allocation of Time in Markets for Labor and Marriage," Economic Journal, 94(4), 863-882.

HaAn, P., And M. Myck (2007): "Safety Net Still in Transition: Labour Market Incentive Effects of Extending Social Support in Poland," IZA Discussion Paper No. 3157, IZA Bonn. 
McFadden, D. (1974): "Conditional Logit Analysis of Qualitative Choice Behavior," in Frontiers in Econometrics, ed. by P. Zarembka. Academic Press, New York.

Myck, M., O. Bargain, M. Beblo, D. Beninger, R. Blundell, R. CarRasco, M. Chiuri, F. Laisney, V. Lechene, E. Longobardi, M. N., J. Ruiz-Castillo, and F. Vermeulen (2006): "The working families' tax credit and some European tax reforms in a collective setting," Review of Economics of the Household, 4, 129-158.

VAn Soest, A. (1995): "Structural Models of Family Labor Supply: A Discrete Choice Approach," Journal of Human Resources, 30, 63-88.

Vermeulen, F. (2002): "Collective household models: principles and main results," Journal of Economic Surveys, 16(4), 533-564.

Vermeulen, F., O. Bargain, M. Beblo, D. Beninger, R. Blundell, R. CarRasco, M. Chiuri, F. Laisney, V. Lechene, E. Longobardi, M. N., M. Myck, And J. Ruiz-Castillo (2006): "Collective models of labor supply with nonconvex budget sets and nonparticipation: A calibration approach," Review of Economics of the Household, 4, 113-127.

\section{Appendix: figures and additional tables}


Figure 1: Degree of sharing and implied replacement ratios for singles in MFHs

Single men no children,

$1 \mathrm{~A}$

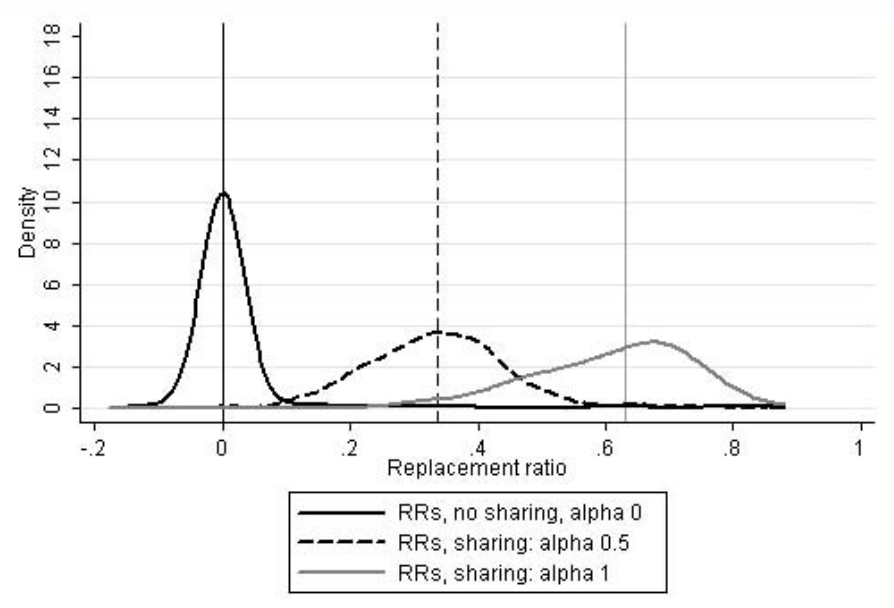

Single women, no children

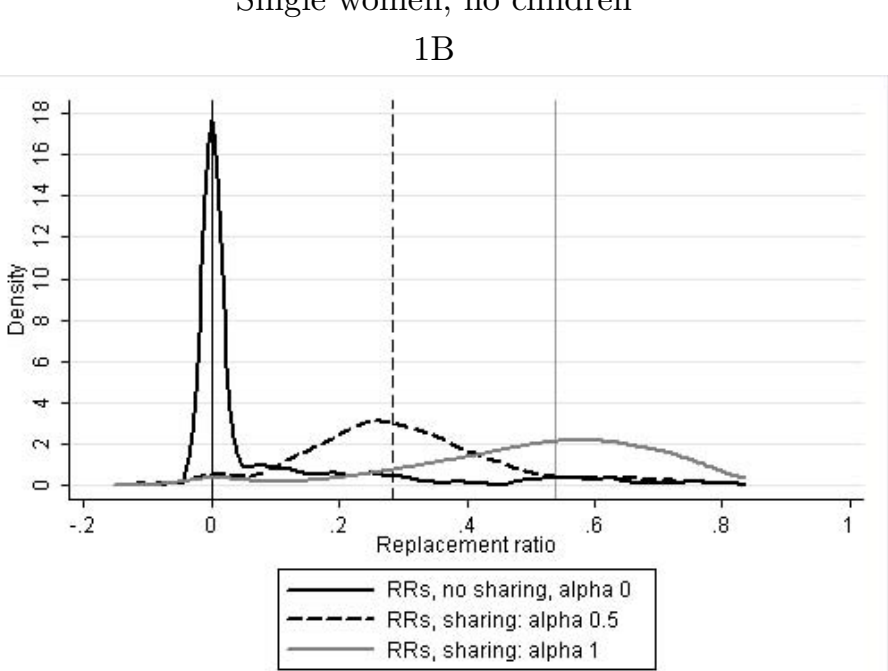

Note: Replacement ratios computed as a ratio of income out of work to income in full-time work. Vertical lines represent respective median RRs.

Source: Authors' calculations using the SIMPL micro-simulation model. BBGD 2005.

Table 8: LS flexible families and their households

\begin{tabular}{lccccc}
\hline \hline & $\begin{array}{c}\text { Couples } \\
\text { both flexible } \\
\text { (a-couple) }\end{array}$ & $\begin{array}{c}\text { Couples } \\
\text { man flexible } \\
\text { (m-couple) }\end{array}$ & $\begin{array}{c}\text { Couples } \\
\text { woman flexible } \\
\text { (f-couple) }\end{array}$ & Single & Total \\
No other family & 7,105 & 1,216 & 1,022 & 2,258 & 11,601 \\
One other F, LS fixed & 1,510 & 315 & 240 & 1,732 & 3,797 \\
Two other F, both LS fixed & 261 & 70 & 48 & 221 & 600 \\
Three or more other F, all LS fixed & 26 & 4 & 8 & 33 & 71 \\
One other F, LS flex a-couple & 64 & 41 & 49 & 324 & 478 \\
One other F, LS flex m-couple & 41 & 4 & 16 & 166 & 227 \\
One other F, LS flex f-couple & 49 & 16 & 14 & 148 & 227 \\
One other F, LS flex single & 324 & 166 & 148 & 480 & 1,118 \\
Two other F, one LS flex a-couple, one fixed & 22 & 7 & 14 & 121 & 164 \\
Two other F, one LS flex m-couple, one fixed & 7 & 0 & 1 & 72 & 80 \\
Two other F, one LS flex f-couple, one fixed & 14 & 1 & 8 & 37 & 60 \\
Two other F, one LS flex single, one fixed & 121 & 72 & 37 & 446 & 676 \\
Other & 91 & 52 & 46 & 546 & 735 \\
Total & 9,635 & 1,964 & 1,651 & 6,584 & 19,834 \\
\hline \hline
\end{tabular}

Source: Authors' classification using BBGD, 2005. 
Table 9: LS flexible singles and their households.

\begin{tabular}{lccc|ccc}
\hline \hline & \multicolumn{3}{c}{ Without children } & \multicolumn{3}{c}{ With children } \\
& Men & Women & Total & Men & Women & Total \\
No other family & 415 & 733 & 1148 & 68 & 1042 & 1110 \\
One other F, LS fixed & 762 & 509 & 1271 & 35 & 426 & 461 \\
Two other F, both LS fixed & 88 & 77 & 165 & 6 & 50 & 56 \\
Three or more other F, all LS fixed & 16 & 9 & 25 & 1 & 7 & 8 \\
One other F, LS flex a-couple & 168 & 126 & 294 & 1 & 29 & 30 \\
One other F, LS flex m-couple & 100 & 57 & 157 & 0 & 9 & 9 \\
One other F, LS flex f-couple & 80 & 57 & 137 & 1 & 10 & 11 \\
One other F, LS flex single & 154 & 223 & 377 & 13 & 90 & 103 \\
Two other F, one LS flex a-couple, one fixed & 77 & 36 & 113 & 0 & 8 & 8 \\
Two other F, one LS flex m-couple, one fixed & 49 & 20 & 69 & 0 & 3 & 3 \\
Two other F, one LS flex f-couple, one fixed & 22 & 11 & 33 & 0 & 4 & 4 \\
Two other F, one LS flex single, one fixed & 227 & 157 & 384 & 5 & 57 & 62 \\
Other & 308 & 169 & 477 & 7 & 62 & 69 \\
Total & 2466 & 2184 & 4650 & 137 & 1797 & 1934 \\
\hline \hline
\end{tabular}

Source: Authors' classification using BBGD, 2005. 